\title{
Effect of Vinblastine in Vivo on Ultrastructure and Insulin Releasing Capacity of the B-Cell Following Sulphonylurea and Isopropyl-Noradrenaline*
}

\author{
L. E. Ericson and I. Lundquist \\ Dept. of Anatomy, Univ. of Göteborg and Dept. of Pharmacology, Univ. of Lund, Sweden
}

Received: March 4, 1974, and in revised form: July 10, 1975

\begin{abstract}
Summary. The effect of vinblastine in vivo on ultrastructure and insulin releasing capacity of the B-cell was studied in mice. Treatment with vinblastine (1.1 umole/mouse) resulted in a $75 \%$ decrease of the amount of normal microtubules and the appearance of characteristic paracrystals. Basal plasma immunoreactive insulin levels were depressed to about $60 \%$ of the control level. The dose-response pattern for insulin release (first phase) following two chemically unrelated insulin secretagogues, the potent sulphonylurea derivative, glibenclamide, and the $\beta$-adrenergic agonist $L$-isopropylnoradrenaline, ( $L$-IPNA), was tested with and without vinblastine pretreatment. The dose-response curves for $L$-IPNAinduced insulin release in vinblastine-treated and control animals
\end{abstract}

did not deviate significantly from each other, whereas insulin release following glibenclamide was almost totally suppressed by vinblastine except at the lowest dose level. Injection of maximal doses of glibenclamide or $L$-IPNA did not alter the ultrastructural changes induced by vinblastine in the B-cells. It is suggested that the microtubular system of the B-cell might play a minor role for certain insulin-releasing processes and/or that vinblastine might have other important effects on the insulin secretory machinery.

Key words: Blood glucose, glibenclamide, immunoreactive insulin, isopropylnoradrenaline, mouse, pancreatic islets, ultrastructure, vinblastine.
In 1968 it was suggested that microtubules in the pancreatic B-cell were involved in the intracellular $\beta$-transport of - granules during the process of exocytosis [4]. This hypothesis was based upon the ultrastructural demonstration of microtubules in the $\mathrm{B}$-cell and the observation that a mitotic spindleinhibitor, colchicine, inhibited insulin secretion by isolated rat islets in vitro [4]. A number of subsequent investigations have confirmed and extended this original observation on the possible role and function of the microtubular system in insulin release, showing with various in vitro techniques that both the Vinca alkaloids, vincristine and vinblastine, which disrupt microtubules, and microtubular stabilizers, such as deuterium oxide $\left(\mathrm{D}_{2} \mathrm{O}\right)$ and hexylene glycol, produce significant inhibition of insulin release induced by glucose or sulphonylurea [5, 10-12].

The aim of the present investigation was to study the effect of vinblastine in vivo on the ultrastructure and the insulin releasing capacity of the B-cell. Evidence will be presented showing that treatment with vinblastine, resulting in disruption of microtubules and formation of paracrystals of microtubular protein in the B-cell, only partly inhibits basal insulin secretion. Furthermore, the insulin dose-response curve

* This study was supported by the Swedish Medical Research Council, Grants No. 12X-537; 04X-4286;04P-4289 and "Jubileumsfonden" (Ferrosan AB, Malmö, Sweden). following the sulphonylurea compound glibenclamide is markedly suppressed by vinblastine pretreatment while almost unaffected by vinblastine following a maximal dose of the $\beta$-adrenergic agonist $L$-isopropylnoradrenaline ( $L$-IPNA).

\section{Materials and Methods}

\section{Animals}

Female mice of the NMRI strain (Laboratory Animal Breeding, Laven, Denmark) weighing 20$30 \mathrm{~g}$ were used. The animals were kept on a standard pellet diet (Astra-Ewos, Södertälje, Sweden) and tap water ad libitum before and throughout the experiments.

\section{Drugs}

Vinblastine sulphate was generously provided by Eli Lilly Co., Indianapolis, Ind., U.S.A., glibenclamide by Boehringer Mannheim GmbH, Germany, and $L$-isopropylnoradrenaline ( $L$-IPNA) by Hässle $\mathrm{AB}$, Göteborg, Sweden.

\section{Experimental}

Vinblastine (1.1 $\mu$ mole/mouse), glibenclamide, $L$-IPNA and saline were always injected into a tail 
vein in a volume of $0.2 \mathrm{ml} / 20 \mathrm{~g}$ mouse. Blood sampling was performed by the orbital bleeding technique [15]. Plasma insulin levels (peak levels) were recorded $2 \mathrm{~min}$ (glibenclamide) and $5.5 \mathrm{~min}$ ( $L$-IPNA) following the injection of the drugs, respectively. Repeated experiments in this laboratory have shown that maximum concentration of immunoreactive insulin in mouse plasma following a rapid intravenous injection of glibenclamide and $L$-IPNA, respectively, is achieved after 1.5-2.5 min (glibenclamide) and 5-6 min ( $L$-IPNA). Vinblastine was always given about $2.5 \mathrm{~h}$ before blood sampling. Blood glucose levels were determined enzymatically [14]. The concentrations of insulin in plasma were determined by the method of Heding [3] using ${ }^{125}$ I-labelled pig insulin and guinea pig anti-pig-insulin. Student's t-test was employed for tests of significance.

\section{Electron Microscopy}

Specimens from 30 mice were examined. The animals were given $1.1 \mu$ mole vinblastine intravenously in the tail $2.5 \mathrm{hrs}$ prior to the injection of either glibenclamide $(0.5 \mu \mathrm{mole} / \mathrm{kg}, L$-IPNA $(1.37$ $\mu \mathrm{mole} / \mathrm{kg}$ ) or saline as above. After 2 min (glibenclamide, saline) or $5.5 \mathrm{~min}$ ( $L$-IPNA, saline) the pancreatic glands were fixed by perfusion with $3 \%$ glutaraldehyde in $0.075 \mathrm{M}$ sodium cacodylate under ether anaesthesia. Small pieces of the splenic part of the pancreas were immersed overnight in a similar glutaraldehyde solution and they were then postfixed in $1 \%$ osmium tetroxide in $0.2 \mathrm{M}$ sodium cacodylate for $2 \mathrm{hrs}$. Specimens were embedded in Epon and sections were cut on a LKB Ultrotome. Pancreatic

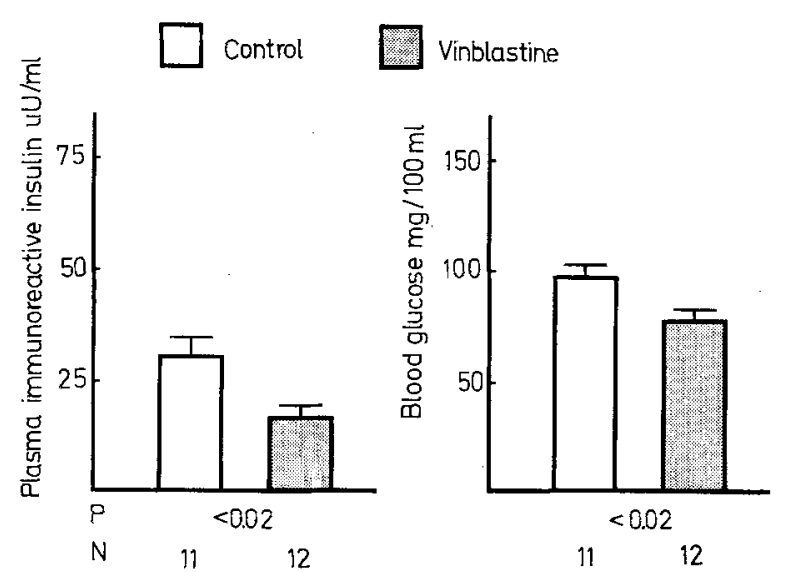

Fig. 1. Basal immunoreactive plasma insulin levels and basal blood glucose levels in animals injected with either saline (white columns) or vinblastine (stippled columns) -2.5 hrs before blood sampling. Bars indicate standard error of the mean. $\mathrm{P}=$ probability level of random differences. $\mathbf{N}=$ number of animals in each group islets were identified in $1 \mu$ thick sections stained with toluidine blue. Sections for electron microscopy were stained with uranyl acetate and lead citrate and were examined in a Philips EM 300 electron microscope.

For evaluation of the amount of microtubules present in B-cells, 7-8 randomly chosen areas of each islet, together representing a cytoplasmic area of B-cells of about $250 \mu^{2}$, were photographed in the electron microscope. For each islet the total length and number of microtubular profiles were recorded as well as the number of vinblastine-induced paracrystals. Transversely sectioned microtubules were excluded. The values obtained were related to the area of B-cell cytoplasm which was estimated by point counting.

\section{Results}

\section{Effect of Vinblastine on Basal Levels of Blood Glucose and Plasma Insulin and on B-Cell Ultrastructure}

The effect of intravenously administered vinblastine, $1.1 \mu \mathrm{mole} / \mathrm{mouse}$, on basal levels of blood glucose and plasma immunoreactive insulin was investigated $2.5 \mathrm{hrs}$ after injection of the drug (Fig. 1). Control animals received saline. From Fig. 1 appears that basal plasma insulin level in the vinblastine-treated group (stippled columns) was moderately but significantly depressed to about $60 \%$ of that of the saline-treated control group (white columns). Fig. 1 also shows that basal blood glucose level tended to decrease in the vinblastine-treated animals suggesting other effects on carbohydrate metabolism as well.

In uninjected mice or mice injected with saline only, microtubules were found in the pancreatic B-cells (Fig. 2). Microtubules in B-cells had a diameter of $230-240 \AA$ and did not show any obvious location of preference.

In mice injected with vinblastine $2.5 \mathrm{hrs}$ prior to the fixation the amount of microtubules, evaluated either as the length or as the number of microtubular profiles, was reduced to about $25 \%$ of that found in mice not injected with vinblastine (Table 1). In addition, treatment with vinblastine resulted in the formation of characteristic paracrystals (Fig. 3). Both the disappearance of normal microtubules and the appearance of paracrystals are related to the binding of vinblastine to microtubular protein $[1,17]$. In a section of a pancreatic islet of ordinary size, 5-10 such paracrystals were found. They did not display any preferential site of location. All types of organelles present in B-cells were associated with the 


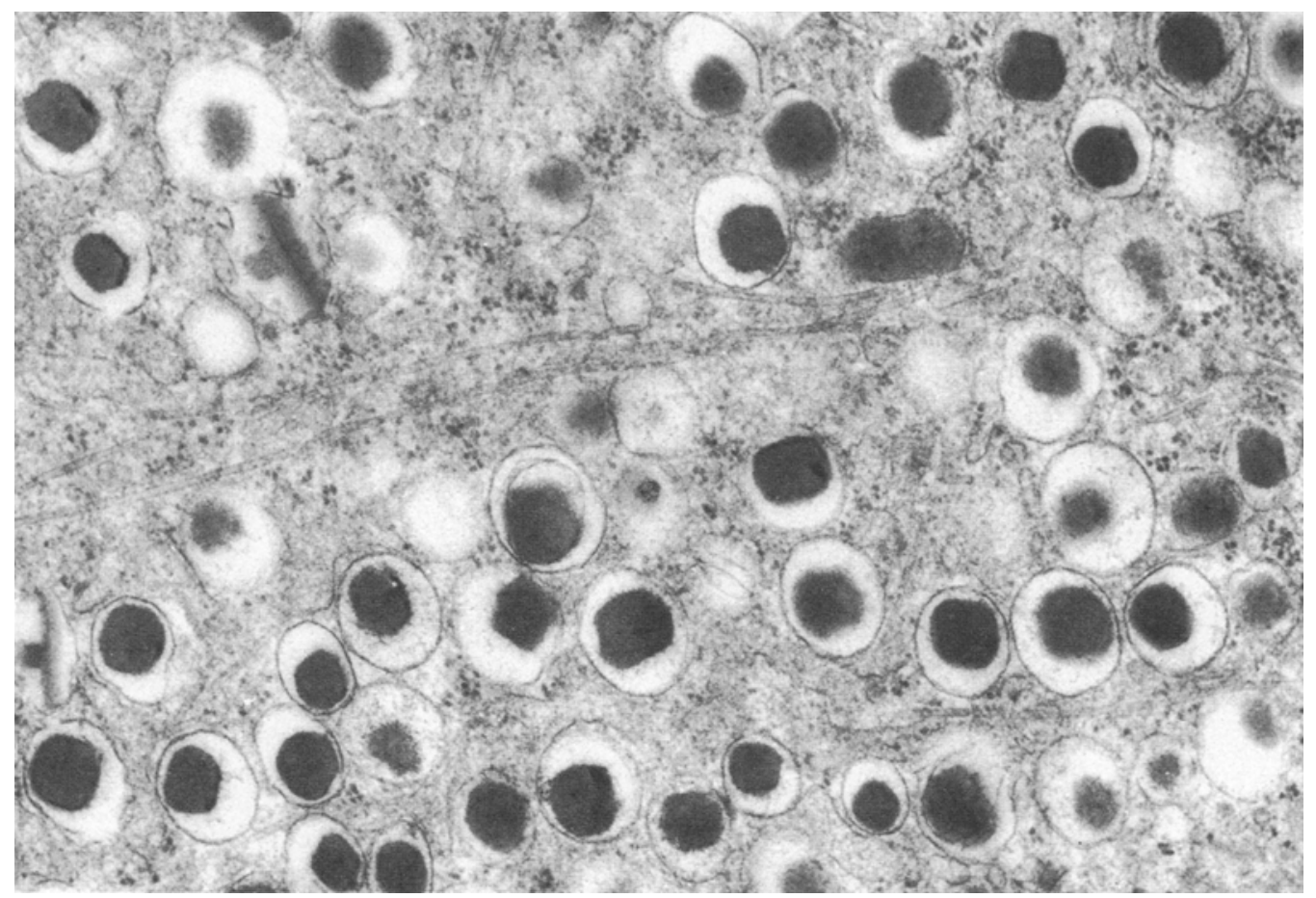

Fig. 2. Electron micrograph of a B-cell from a control mouse showing several microtubules transversing the cytoplasm. $\times 37,500$

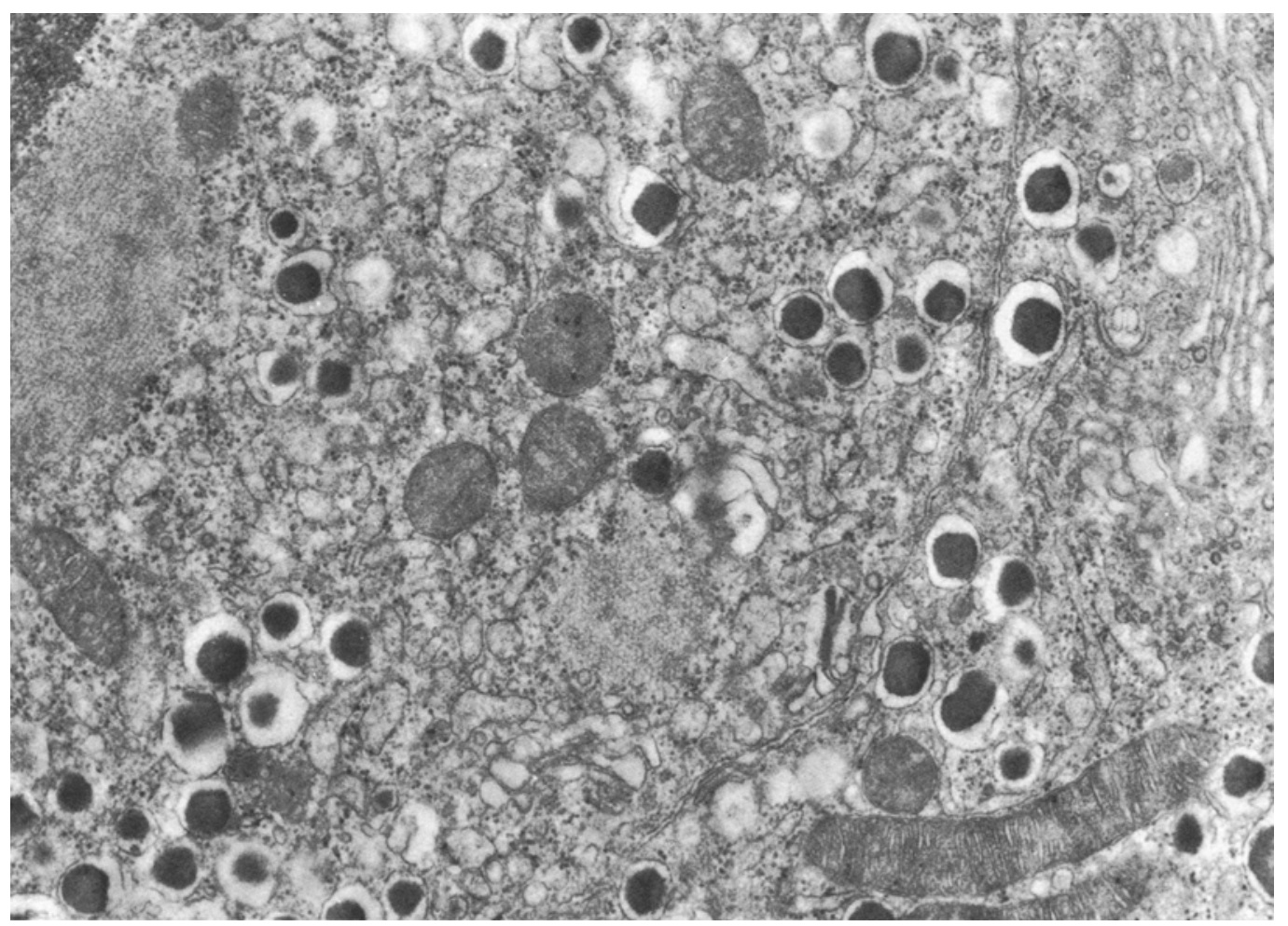

Fig. 3. From a mouse injected with vinblastine 2.5 hrs prior to the fixation. Microtubules are absent. Two typical paracrystals, one longitudinally sectioned (left border), another transversely sectioned (center) are present. $\times 24,500$ 
paracrystals as endoplasmic reticulum (Figs. 3, 7), Golgi apparatus (Fig. 6), mitochondria (Fig. 7) or $\beta$-granules (Figs. 6, 7). The associated $\beta$-granules often lacked their dense cores (Fig. 7) but otherwise no alteration in structure or distribution of organelles could be discerned. When longitudinally sectioned the paracrystals were oval or rectangular, the longest profile observed measuring about $4 \mu \mathrm{m}$ in length, and showed a substructure of parallel, electron-opaque lines with approximately $280 \AA$ interdistance (Figs. 3, $6,7)$. In cross-section the paracrystals were spherical and presented a honeycomb-like arrangement (Fig. 3). Aggregated microtubules with associated arrays of ribosomes were also observed in vinblastine-treated mice (Fig. 4).

Table 1. Quantitative evaluation of the in vivo effects of vinblastine, administered with and without insulin secretagogues, on the microtubules of the B-cell

\begin{tabular}{lccc}
\hline Treatment & $\begin{array}{l}\text { Length }(\mu \mathrm{m}) \text { of } \\
\text { microtubules }\end{array}$ & $\begin{array}{l}\text { Number of } \\
\text { microtubules }\end{array}$ & $\begin{array}{c}\text { Number of } \\
\text { paracrystals }\end{array}$ \\
\hline $\begin{array}{l}\text { Saline }+ \\
\text { saline (9) }\end{array}$ & $116.4 \pm 4.8$ & $23.9 \pm 0.8$ & - \\
$\begin{array}{l}\text { Vinblastine }+ \\
\text { saline (6) }\end{array}$ & $27.7 \pm 2.7$ & $6.2 \pm 0.8$ & $1.9 \pm 0.5$ \\
$\begin{array}{l}\text { Vinblastine }+ \\
\text { glibenclamide } \\
\text { Vinblastine }+ \\
\text { L-IPNA (5) }\end{array}$ & $30.2 \pm 3.6$ & $5.9 \pm 0.6$ & $1.3 \pm 0.3$ \\
\hline
\end{tabular}

The given mean values ( \pm standard error of the mean) are those obtained for $100 \mu \mathrm{m}^{2}$ of B-cell cytoplasm. Vinblastine was given 2.5 hrs prior to the injection of either saline, a maximal dose of glibenclamide $(0.5 \mu \mathrm{mole} / \mathrm{kg})$ or a maximal dose of $L$-IPNA $(1.37$ $\mu$ mole $/ \mathrm{kg}$ ). Number of islets analysed are indicated in brackets. Differences between means for the control group (saline + saline) and corresponding values for other groups are significant $(\mathbf{P}<$ 0.001 )

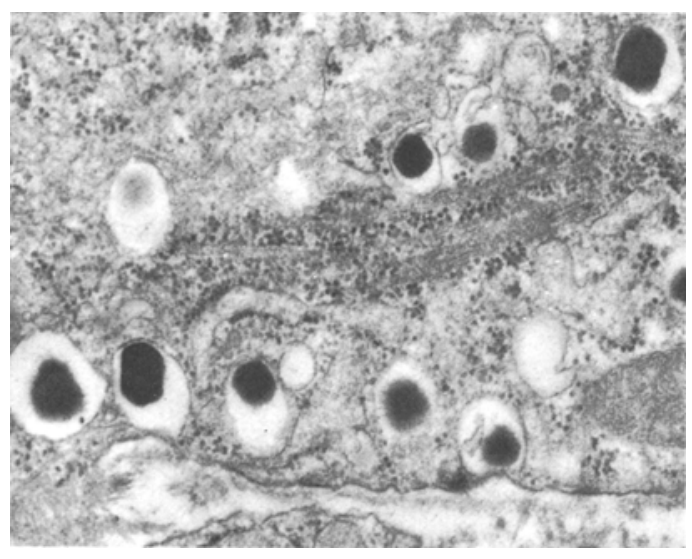

Fig. 4. From a mouse injected with vinblastine. Aggregated microtubules are associated with ribosomes. $\times 34,000$

\section{Effect of Vinblastine on Insulin Releasing Capacity and Ultrastructure of the B-Cell Following Stimulation by Glibenclamide or L-IPNA}

To discover if the administration of the chemically unrelated insulin stimulators glibenclamide and $L$-IPNA, respectively, would reveal any difference in their ability to release insulin in vinblastine-treated animals the following experiments were designed (Fig. 5). Groups of animals were pretreated with either vinblastine or saline $2.5 \mathrm{hrs}$ prior to the experiment. After a rapid intravenous injection of different doses of glibenclamide or $L$-IPNA, respectively, peak levels of the acutely released insulin were determined. From Fig. 5 it appears that glibenclamide-induced insulin release was significantly depressed (except at the lowest dose) in the vinblastine-treated groups, while insulin release induced by $L$-IPNA was practically unaffected by vinblastine pretreatment. The highest doses of glibenclamide and $L$-IPNA used in this experiment, were maximal doses.

Injection of a maximal dose of glibenclamide or $L$-IPNA did not alter the ultrastructural changes induced by vinblastine in B-cells (Figs. 6, 7). Thus, both in L-IPNA-injected animals, in which secretion of insulin was not inhibited, and in glibenclamide-injected animals, in which secretion of insulin was inhibited, the amount of microtubules in B-cells was reduced to the same level as found in mice injected with vinblastine alone (Table 1). Neither was the number of paracrystals present in B-cells influenced by injection of $L$-IPNA or glibenclamide (Figs. 6, 7; Table 1).

\section{Discussion}

Addition of vinblastine and other mitotic-spindle inhibitors to pancreatic slices or isolated islets in vitro is known to destroy the microtubular system in the B-cells and to depress insulin secretion [4, 5, 10-12]. From our data presented above it is obvious, with regard to vinblastine, that these effects can, be reproduced also in vitro. The basal levels of plasma immunoreactive insulin were moderately depressed to about $60 \%$ of the control level and the B-cells contained paracrystals comparable to those induced by vincristine in vitro [12]. Microtubules were only occasionally found. Both the disappearance of normal microtubules and the appearance of paracrystals are related to the binding of vinblastine to microtubular protein $[1,17]$. However, in spite of its effects on the microtubular system vinblastine did not apparently affect the general morphology of the cell. 

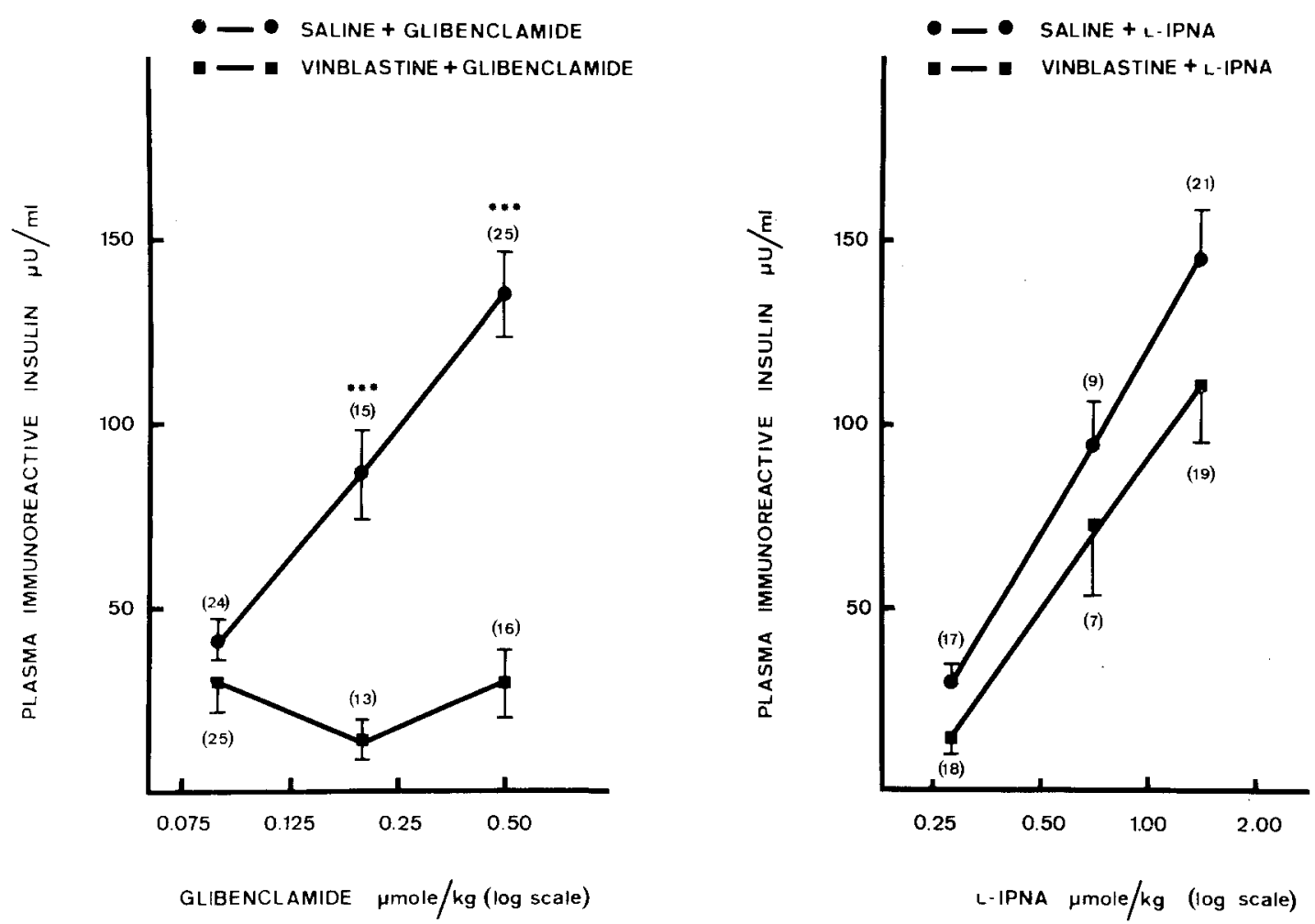

Fig. 5. Dose response curves for insulin release induced by glibenclamide (left) and $L$-IPNA (right), respectively, in mice pretreated with either saline or vinblastine $(1.1 \mu$ mole/mouse) $2.5 \mathrm{hrs}$ prior to the experiment. Ordinate: Increase in plasma immunoreactive insulin over saline- and vinblastine-treated controls, respectively. Abscissa: Dose of glibenclamide or $L$-IPNA ( $\mu$ mole $/ \mathrm{kg}$ body weight) (log scale). Means and standard error of the means are shown. Asterisks $\left({ }^{* * *}\right)$ indicate probability level of random difference $(\mathrm{P}<0.001)$ for saline pretreated versus vinblastine pretreated animals. Figures in parenthesis indicate number of mice

According to current concepts $[5,10]$, the microtubular system in the B-cell is required for insulin secretion to occur. Recent experiments with in vitro perfusion of isolated islets have shown that vinblastine inhibits the first phase of insulin secretion induced by glucose or tolbutamide [5]. Our present data (relevant to the first phase of the insulin secretory process) showing an inhibiting effect by vinblastine on glibenclamide-induced insulin release in vivo appear to confirm and extend a possible role for the microtubules in sulphonylurea-induced insulin release. However, the rather unexpected finding (Fig. 5) that insulin release induced by $L$-IPNA was practically unaffected by vinblastine treatment raises some doubts as to the absolute importance of the microtubular system for certain insulin secretory processes in vivo. Whether the larger effect by vinblastine on insulin release in response to glibenclamide than on the response to $L$-IPNA reflects a qualitative or a quantitative difference cannot be answered at present. However, it is obvious that glibenclamide (except at the lowest dose level) is more sensitive to the inhibitory effect of vinblastine than is $L$-IPNA.

It has to be stressed that in the B-cells of animals injected with vinblastine and $L$-IPNA, microtubular profiles were rare findings and that paracrystals appeared in about the same number as in mice injected with vinblastine and in addition given glibenclamide or saline (Table 1).

The possibility also exists, that the inhibiting action of vinblastine on glibenclamide-induced insulin release in vivo (Fig. 5) might be the result of an effect of vinblastine on B-cell constituents other than microtubules, e.g. on the cell membrane or on the lysosomes which recently have been suggested to be involved in the induction of sulphonylurea-stimulated insulin release [6-9]. A blocking effect by colchicine and vinblastine on leukocyte lysosomes was described several years ago [13]. Moreover, the above observation that different or partly different insulin secretory mechanisms might be operating after stimulation by sulphonylureas and $L$-IPNA, respectively, is supported by the recent finding that a maximal dose of gliben- 


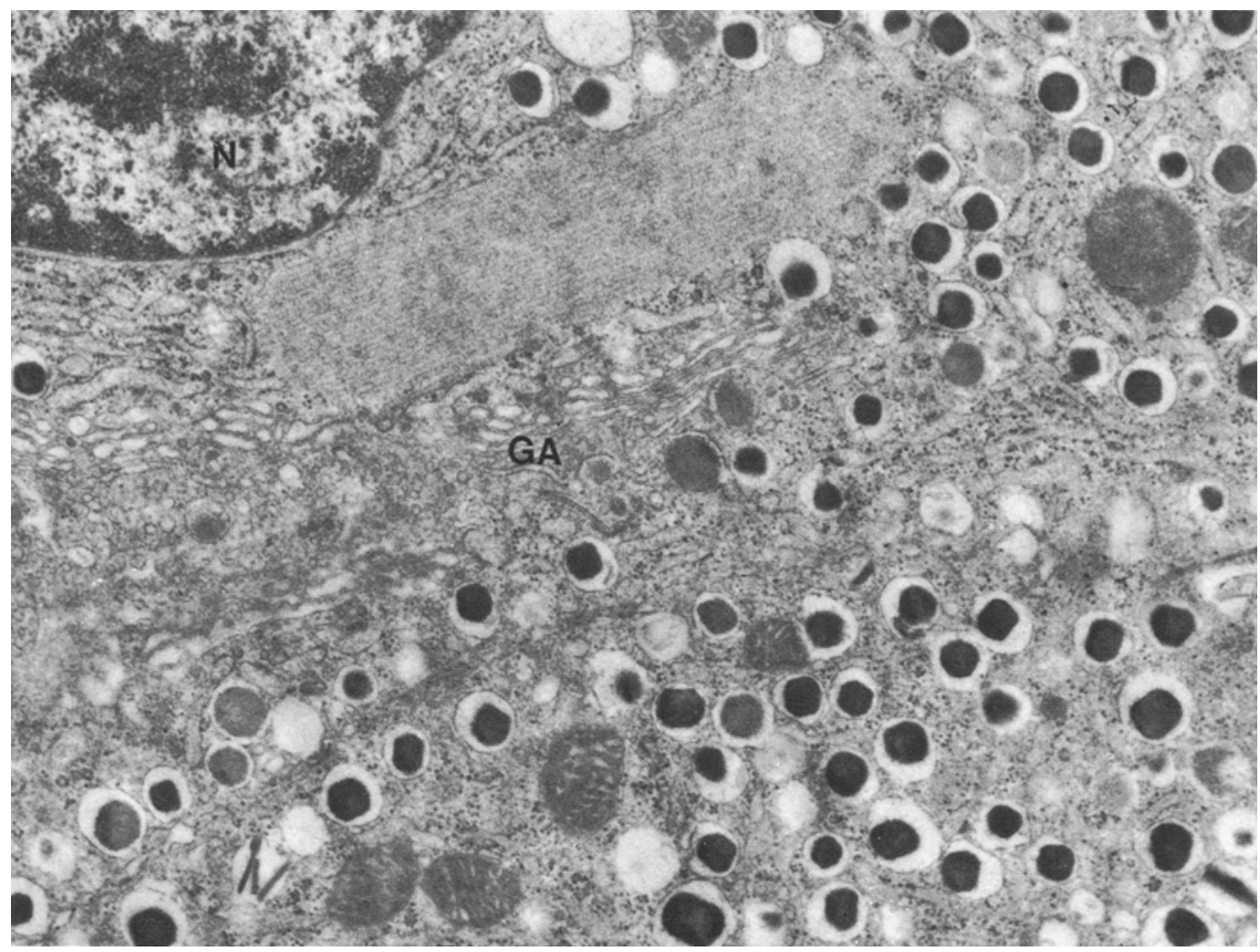

Fig. 6. Electron micrographs of B-cells from a mouse injected with vinblastine and $L$-IPNA. A rectangular, longitudinally sectioned, paracrystal is situated close to the nucleus (N) and to the Golgi apparatus (GA). Several $\beta$-granules are also associated with the paracrystal. Microtubules are absent. $\times 19,500$

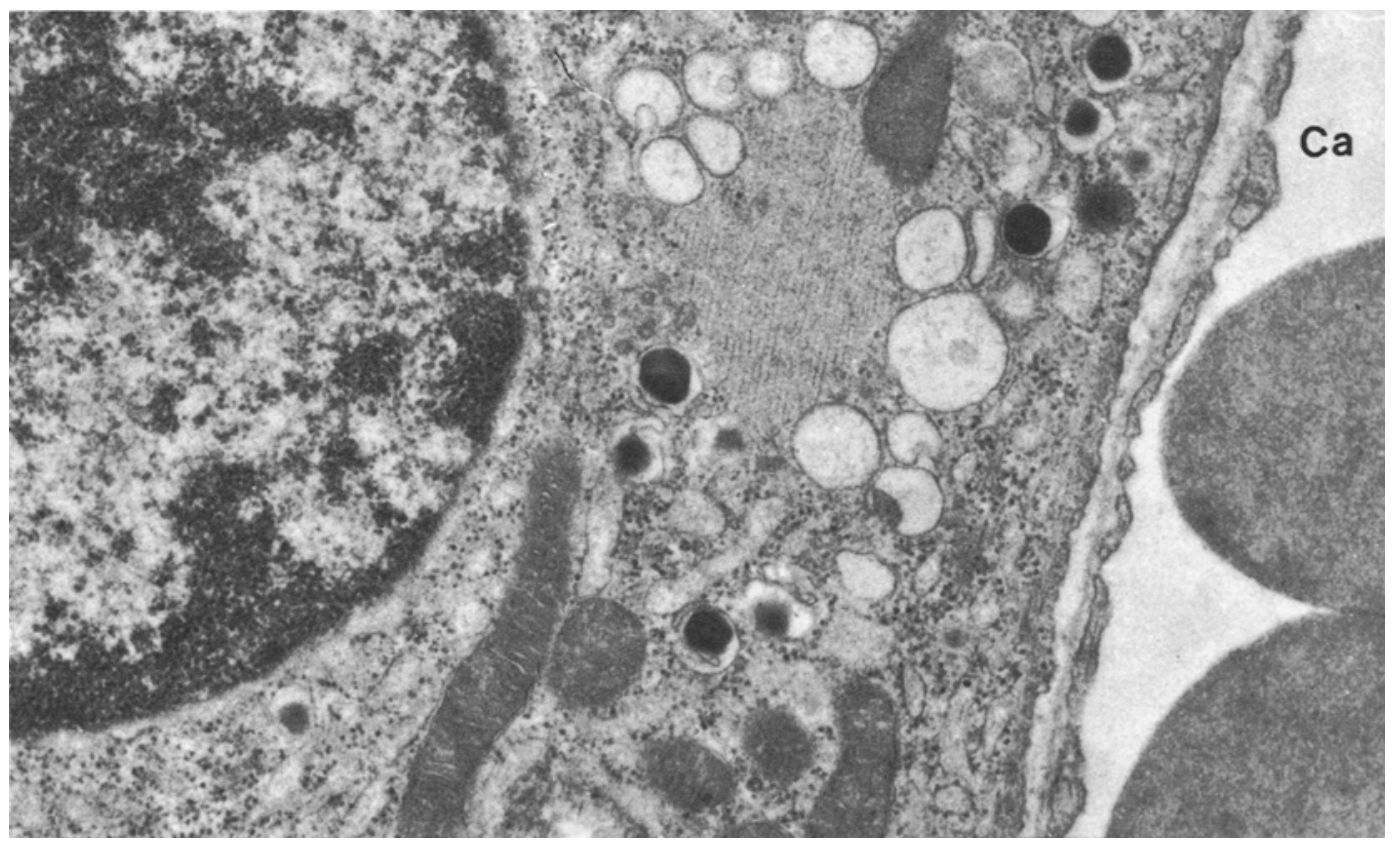

Fig. 7. Mice injected with vinblastine and glibenclamide. The paracrystal is associated with mitochondria and empty $\beta$-granules. A part of a capillary (Ca) with red blood cells is included. $\times 25,000$ 
clamide released different amounts of insulin in three different strains of mice, while the insulin response to a maximal dose of $L$-IPNA was of equal magnitude in all three strains [9]. In this context it should also be mentioned that maturity onset diabetics have been shown to have a normal insulin response after IPNA injection, whereas their response to tolbutamide or glucose was considerably reduced or abolished $[2,16]$.

However, whether other B-cell constituents than the microtubules are affected by vinblastine remains to be elucidated. Furthermore, it has to be borne in mind that the effects of vinblastine on the B-cell is not necessarily identical to the effects of other microtubular poisons such as colchicine and vincristine. Studies are now in progress to further investigate the in vivo effects of vinblastine, vincristine, and colchicine on the ultrastructure and insulin secretory capacity of the B-cell following various insulinogenic stimulators.

\section{References}

1. Bryan, J.: Definition of three classes of binding sites in isolated microtubule crystals. Biochemistry (Wash.) 11, 2611-2616 (1972b)

2. Deckert, T., Birk Lauridsen, U., Nistrup Madsen, S., Mogensen, P.: Insulin response to glucose, tolbutamide, secretin, and isoprenaline in maturity-onset diabetes mellitus. Dan. med. Bull. 19, 222-226 (1972)

3. Heding, L.: A simplified insulin radioimmunoassay method. In: Labelled proteins in tracer studies (ed. L. Donato et al.) pp. 345-350. Brussels: Euratom 1966

4. Lacy, P. E., Howell, S. L., Young, D. A., Fink, C. J.: New hypothesis of insulin secretion. Nature 219, 1177-1179 (1968)

5. Lacy, P. E., Walker, M. O., Fink, C. J.: Perfusion of isolated rat islets in vitro. Participation of the microtubular system in the biphasis release of insulin. Diabetes 21, 987-998 (1972)

6. Lundquist, I.: Insulin secretion. Its regulation by monoamines and acid amyloglucosidase. Acta physiol. scand. (suppl.) 372, $1-47(1971)$
7. Lundquist, I.: Acid amyloglucosidase and carbohydrate regulation. III. The induction of sulphonylurea-stimulated insulin release and its dependence on intracellular monoamines. Horm. Metab. Res. 4, 341-348 (1972)

8. Lundquist, I.: Significance of acid amyloglucosidase in sulphonylurea-induced insulin release. Diabetologia 10, 717-724 (1974)

9. Lundquist, I., Lövdahl, R.: Islet amyloglucosidase and sulphonylurea-stimulated insulin release in three different strains of mice. Horm. Metab. Res. 7, 6-9 (1975)

10. Malaisse, W. J., Malaisse-Lagae, F., Walker, M. O., Lacy, P.E.: The stimulus-secretion coupling of glucose-induced insulin release. V. The participation of a microtubular-microfilamentous system. Diabetes 20, 257-265 (1971)

11. Malaisse, W. J., Mahy, M., Brisson, G. R., Malaisse-Lagae, F.: The stimulus-secretion coupling of glucose-induced insulin release. VIII. Combined effects of glucose and sulfonylureas. Europ. J. clin. Invest. 2, 85-90 (1972)

12. Malaisse-Lagae, F., Greider, M. H., Malaisse, W. J., Lacy, P. E.: The stimulus-secretion coupling of glucose-induced insulin release. IV. The effect of vincristine and deuterium oxide on the microtubular system of the pancreatic B-cell. J. cell. Biol. 49, 530-535 (1971)

13. Malawista, S. E.: Colchicine: A common mechanism for its anti-inflammatory and anti-mitotic effects. Arthr. and Rheum. 11, 191-197 (1968)

14. Marks, V.: An improved glucose oxidase method for determining blood, C. S.F. and urine glucose levels. Clin. chim. Acta 4, 395-401 (1959)

15. Rerup, C., Lundquist, I.: Blood glucose level in mice. I. Evaluation of a new technique of multiple serial sampling. Acta endocr. (Kbh) 52, 357-367 61966)

16. Robertson, R. P., Porte, D. Jr.: The glucose receptor. A defective mechanism in diabetes mellitus distinct from the beta adrenergic receptor. J. clin. Invest. 52, 870-876 (1973)

17. Wilson, L.: Properties of colchicine binding protein from chick embryo brain. Interactions with Vinca alkaloids and podophyllotoxin. Biochemistry (Wash.) 9, 4999-5007 (1970)
Dr. L. E. Ericson
Dept. of Anatomy
Univ. of Göteborg
Fack
S-400 33 Göteborg 33
Sweden 